\title{
Linear polyethylenimine-plasmid DNA nanoparticles are ototoxic to the cultured sensory epithelium of neonatal mice
}

\author{
HAN ZHOU ${ }^{1 *}$, XIAOFENG MA ${ }^{1 *}$, YONGZE LIU ${ }^{2}$, LEI DONG $^{3}$, YI LUO ${ }^{3}$, GUANGJIE ZHU $^{1}$, \\ XIAOYUN QIAN ${ }^{1}$, JIE CHEN $^{1}$, LIN LU $^{1}$, JUNGUO WANG ${ }^{1}$ and XIA GAO ${ }^{1}$ \\ ${ }^{1}$ Department of Otorhinolaryngology, Nanjing Drum Tower Hospital, Nanjing, Jiangsu 210008; \\ ${ }^{2}$ Department of Clinical Medicine, Medical School of Nanjing University, Nanjing, Jiangsu 210093; \\ ${ }^{3}$ State Key Laboratory of Pharmaceutical Biotechnology, School of Life Sciences, \\ Nanjing University, Nanjing, Jiangsu 210093, P.R. China
}

Received April 17,2014; Accepted January 15, 2015

DOI: $10.3892 / \mathrm{mmr} .2015 .3306$

\begin{abstract}
Polyethylenimine (PEI) has been demonstrated to be an effective non-viral synthetic polymer for efficient gene delivery amongst various cell types in vitro and in vivo. In the present study, $25 \mathrm{kDa}$ linear PEI (L-PEI) was used to transfer plasmid DNA (pDNA), encoding the enhanced green fluorescent protein reporter gene, into the cultured cochlear epithelium of neonatal mice. The $25 \mathrm{kDa}$ L-PEI/pDNA nanoparticles were generated in phosphate-buffered saline prior to transfection. Sensory epithelial cells were transfected using an appropriate weight ratio of L-PEI and pDNA. However, the use of higher L-PEI/pDNA ratios, which result in the generation of a greater number of nanoparticles, induced significant damage to the sensory epithelial cells, as demonstrated by immunofluorescent and transmission electron microscopy analyses. These results indicated that precautionary measures are required with regard to the use of PEI nanoparticles in nanomedicine, and emphasized the requirement for thorough physicochemical characterization and toxicity testing for each polymer vector prior to the construction of nanotechnology systems for use in clinical applications. The development of effective management techniques for potential nano-ototoxicity risks is of considerable significance to the clinical applications of nanoparticles.
\end{abstract}

\section{Introduction}

At present, the majority of cases of sensorineural hearing loss remain incurable. Gene therapy is an effective approach for the

Correspondence to: Dr Xia Gao, Department of Otorhinolarnygology, Nanjing Drum Tower Hospital, 321 Zhongshan Road, Nanjing, Jiangsu 210008, P.R. China

E-mail: xiagaogao@hotmail.com

*Contributed equally

Key words: linear polyethylenimine, nanoparticles, cochlear sensory epithelium, oto-nanotoxicity treatment of genetic disorders of the inner ear, where defective genes may be replaced or novel genes may be introduced into specific cell types to elicit a therapeutic response. Such genetic therapies have received significant attention as they provide potential for the arrest, reversal or cure of deafness $(1,2)$.

Viral vectors, including adenovirus (AV), adeno-associated virus (AAV) and lentivirus (LV), present the advantage of facilitating sustained gene expression within transfected cochlear cells, with the potential for the vector to be dependent upon virus-specific properties. These viral vectors have evolved to be highly efficient gene delivery systems and have been used in various fields of inner ear research. However, while the use of viral vectors offers numerous experimental advantages, they are also associated with certain limitations. Significant challenges which remain for these viral vectors include the induction of the immune response, toxicity of the gene transfer vehicle and potential transformation-associated risks of cells modified by insertional mutagenesis (3-5).

Non-viral gene delivery systems have lower immunogenicity, are comparatively easier to scale up and exhibit enhanced abilities in terms of vector modification and DNA incorporation capacity (6). It has been hypothesized that gene therapy in humans will likely utilize non-viral vectors over viral vectors in the future (6).

Non-viral, amine-containing polymers, including polyethylenimine (PEI), polylysine and polyamidoamine dendrimers have previously been well investigated. These cationic polymers spontaneously form stable complexes with DNA that are able to be employed for gene delivery (7). To date, PEI is one of the most successful non-viral gene carriers reported (8), newly designed and synthesized materials are frequently compared with it and a plethora of PEIs with various molecular weights and structures, have garnered attention. Among them, the $25 \mathrm{kDa}$ linear PEI (L-PEI) is a benchmark, due to its relatively high gene delivery efficiency and availability (9). Apart from uses in cancer therapy, PEIs have been utilized in diverse fields, including neurological research $(10,11)$; however, to date, few studies regarding the use of non-viral vectors have been conducted by otolaryngologists. To the best of our knowledge, Tan et al (14) were the first to introduce L-PEI as a gene vector to the field of inner ear research. 
However, a factor which has not yet gained sufficient attention in the nanomedical field is that nanoparticles are not inherently benign and therefore influence physiological functions at the cellular, subcellular, protein and gene levels $(15,16)$. Nanotoxicology describes the study of the interactions between nanostructures and biological systems, particularly focusing on elucidating the associations between the physiochemical properties (including the size, shape, surface chemistry, composition and aggregation) of nanostructures with the induction of pathophysiological or toxic biological responses (17). The risks associated with individual nanomaterials may differ from their bulk material counterparts due to their altered physiochemical properties (17). To date, suitable standardized in vitro tests and experimental protocols for the evaluation of nanotoxicity have remained unavailable. Whether PEI-based nanoparticles possess nano-ototoxicity, which may result in disadvantages associated with cochlear disruption, has remained to be elucidated. PEI is unable to be effectively eliminated and therefore accumulates over time, highlighting an urgent need for the confirmation of the safety profile of PEI prior to the initiation of PEI-associated clinical trials (16). The present study therefore aimed to identify any potential nano-ototoxicity that PEI nanoparticles may exert on the cultured cochlear epithelium of neonatal mice, and provide a rationale for the use of in vivo animal studies to assess nanotoxicity of various nanoparticles in multiple cell types.

\section{Materials and methods}

Nanoparticle formation. Plasmids encoding the enhanced green fluorescent protein reporter gene (pEGFP-C1) were purchased from Clontech Laboratories, Inc. (Mountain View, CA, USA) and $25 \mathrm{kDa}$ L-PEI was obtained from Sigma-Aldrich (St. Louis, MO, USA). The plasmids were amplified and purified according to the manufacturer's instructions. Briefly, the pEGFP-C1 plasmid was propagated in competent Escherichia coli strain DH5a (Gibco, Rockville, MD, USA) and purified using the Qiagen Endotoxin-Free Plasmid Purification kit (Qiagen, Valencia, CA, USA). The UV absorbance was measured at $260 \mathrm{~nm}$ using a biophotometer (6131; Eppendorf, Hamburg, Germany), in order to determine DNA concentration. The purity of the DNA was confirmed by measuring UV absorbance at 260/280 nm. Stock solutions of L-PEI $(1 \mu \mathrm{g} / \mu \mathrm{l})$ and plasmid DNA (pDNA; $1 \mu \mathrm{g} / \mu \mathrm{l})$ were prepared, and prior to each experiment were combined at various weight ratios of up to $2 \mu \mathrm{g}: 14 \mu \mathrm{g}$ (pDNA/L-PEI). The $\mathrm{pH}$ of the stock L-PEI solution was neutralized using concentrated $\mathrm{HCl}$ (Sunshine Biotechnology Co., Ltd., Nanjing, China). Polyplex formation utilized solutions of equal volumes (50 $\mu \mathrm{l}$ ) with L-PEI being gently added to the plasmid solution. Samples were continuously vortexed during addition and equilibrated at room temperature for $20 \mathrm{~min}$ prior to use. L-PEI was stored in aliquots at $-20^{\circ} \mathrm{C}$ and the polyplex was freshly prepared prior to each individual measurement. Complexes were formed in phosphate-buffered saline (PBS; pH 7.4) (Sangon Biotechnology Co., Ltd., Shanghai, China) unless otherwise stated.

Characterization. The morphologies of the L-PEI/pDNA polyplexes were examined with a JEM-200CX transmission electron microscope (JEOL, Ltd, Tokyo, Japan). Polyplexes were prepared as described above. The samples were prepared as follows: A drop of dilute particle dispersion was spread over a carbon-coated grid (Agar Scientific Ltd., Stansted, UK). The dried specimens were subsequently negatively stained with a drop of $2 \%$ phosphotungstic acid (Sigma-Aldrich) for $30 \mathrm{~min}$ and dried at room temperature.

Agarose gel retardation assay. An agarose gel retardation assay was used to evaluate the binding ability of L-PEI/pDNA. Complexes were prepared in PBS using $2 \mu \mathrm{g}$ pDNA and various weights of L-PEI, ranging from 0 to $14 \mu \mathrm{g}$. Following the addition of appropriate amounts of 6X gel-loading buffer (Thermo Fisher Scientific, Waltham, MA, USA), the samples were electrophoresed on a $1 \%(\mathrm{w} / \mathrm{v})$ agarose gel containing ethidium bromide $(0.5 \mu \mathrm{g} / \mathrm{ml}$ of the gel) in $0.5 \mathrm{X}$ Tris-boric acid-EDTA (Sunshine Biotechnology Co., Ltd.) at 100 V. DNA in the gel was visualized with an ultraviolet illuminator and photographed with a UVIpro gel image system (UVItec, Ltd, Cambridge, UK).

Dissection, culture and transfection procedure of the cochlear explant. Four-day-old C57BL/6J mice (male:female, 1:1) were purchased from the Model Animal Research Center of Nanjing University (Nanjing, China). Animals were housed under pathogen-free conditions, under a natural day/night cycle. All animal experimental procedures were conducted in accordance with the guidelines set by the Animal Care and Use Committee of Nanjing Drum Tower Hospital and Nanjing University (Nanjing, China). A total of 48 four-day-old mouse pups (weighing $1.25 \pm 0.70 \mathrm{~g}$ ) were anesthetized with $\mathrm{CO}_{2}$ and were sacrificed. The experiments were performed in quadruplicate. Dissection and cell culture were conducted as previously described (18). Briefly, following being cleaned with $75 \%$ ethanol (Sangon Biotechnology Co., Ltd.), pups were decapitated on ice and the cochleae were dissected. Soft tissues and cartilage were removed, and the cochlear epithelium was isolated. The specimens were separated into apical, middle and basal turns. The organotypic cultures were maintained in Dulbecco's modified Eagle's medium (HyClone, Thermo Fisher Scientific) supplemented with B27 (Gibco, Invitrogen Life Technologies, Carlsbad, CA, USA) and 10\% fetal bovine serum (HyClone) at $37^{\circ} \mathrm{C}$ in a humidified atmosphere containing $5 \% \mathrm{CO}_{2}$. After $24 \mathrm{~h}$, the culture medium was removed and replaced with polyplex solution and fresh media. Cochlear explants were randomly divided into two groups: Control (without transfection; 0, 24 and $48 \mathrm{~h}$ ) and treatment $(0,24$ and $48 \mathrm{~h}$ post-transfection).

Immunocytochemical analysis. Following the indicated length of incubation, cochlear explants were fixed with $4 \%$ paraformaldehyde for $30 \mathrm{~min}$. Following rinsing with $0.1 \mathrm{mM}$ PBS, the cochlear explants were permeabilized with $0.5 \%$ Triton X-100 in PBS for 20 min and washed three times with PBS. Incubation with PBS containing 5\% horse serum (Sigma-Aldrich) and $0.1 \%$ Triton X-100 (Thermo Fisher Scientific) for $1 \mathrm{~h}$ at room temperature blocked non-specific binding. The explants were subsequently incubated with the following primary immunoglobulin $\mathrm{G}$ antibodies: Unconjugated mouse monoclonal anti- $\beta$-tubulin III (1:200; Sigma-Aldrich) or goat polyclonal 
anti-otoancorin (1:200; Santa Cruz Biotechnology, Inc., Dallas, TX, USA) overnight at $4^{\circ} \mathrm{C}$. The explants were then washed three times with $0.1 \%$ Tween (Sigma-Aldrich) in PBS, and incubated with the following secondary antibodies: Donkey anti-goat Cy3 (1:500; Invitrogen Life Technologies, Carlsbad, CA, USA) or donkey anti-mouse Alexa Flour 647 (1:500; (Invitrogen Life Technologies) overnight at room temperature. Fluorescein isothiocyanate-phalloidin (Sigma-Aldrich) and Hoechst 33342 (Invitrogen Life Technologies) were added to the secondary antibody solution to label hair cell stereocilia and the nuclei. Following staining, samples were mounted in Fluoromount G (Thermo Fisher Scientific). All images were captured using a Nikon confocal laser scanning microscope (TE2000-U; Nikon Corp., Tokyo, Japan), and images were analyzed using Nis-element Basic research software (version 4.0; Nikon Corp.). Each experiment was performed in triplicate. Negative control experiments were performed with the omission of the primary antibody, in order to verify the lack of non-specific binding of the secondary antibody.

Transmission electron microscopy (TEM). For TEM, the cochlear explants were cultured on polyethylene terephthalate membranes (EMD Millipore, Billerica, MA, USA). Samples were collected at various time-points (without transfection, and 0,24 and $48 \mathrm{~h}$ post-transfection) and fixed in $2.5 \%$ glutaraldehyde (Sigma-Aldrich) in PBS at $4^{\circ} \mathrm{C}$ for $6 \mathrm{~h}$, followed by $1 \%$ osmium tetroxide (Sigma-Aldrich) at $4^{\circ} \mathrm{C}$ for 1 hour, dehydration, infiltration and polymerization in araldite. Ultrathin sections (80-100 nm) were post-stained with uranyl acetate (Sigma-Aldrich) for $30 \mathrm{~min}$ in the dark and lead citrate (Sigma-Aldrich) for $6 \mathrm{~min}$. The sections were then examined using a Hitachi-7650 TEM (Hitachi, Ltd, Tokyo, Japan). In all TEM experiments, $2 \mu \mathrm{g}$ pDNA and $14 \mu \mathrm{g}$ L-PEI was used.

Statistical analysis. Values are presented as the mean \pm standard deviation. Statistical variations between the groups were analyzed using the Student-Newman-Keuls-Q test with SAS version 9 software (SAS, Cary, NC, USA). $\mathrm{P}<0.05$ was considered to indicate a statistically significant difference between values.

\section{Results}

Characterization of the PEI-pDNA nanoparticles. The PEI-pDNA nanoparticles were almost spherical with a diameter of $\sim 20-100 \mathrm{~nm}$ (Fig. 1A). In PBS solution they frequently aggregated, forming larger clots.

Agarose gel retardation is achieved with $0.5 \mu \mathrm{g} L-P E I$. A prerequisite for potential polymeric gene carriers is the ability to condense DNA (19). A gel retardation assay was therefore conducted to determine the quantity of L-PEI that was able to condense DNA. The binding of L-PEI to pDNA results in neutralization of the negative charges in the phosphate backbone of DNA; these large electroneutralized complexes are therefore incapable of migrating towards the anode through the agarose gel (20). A series of polyplexes were prepared using the protocol described $(2 \mu \mathrm{g}$ pEGFP-C1 plasmid DNA complexed with $0-14 \mu \mathrm{g}$ L-PEI) in a reduced
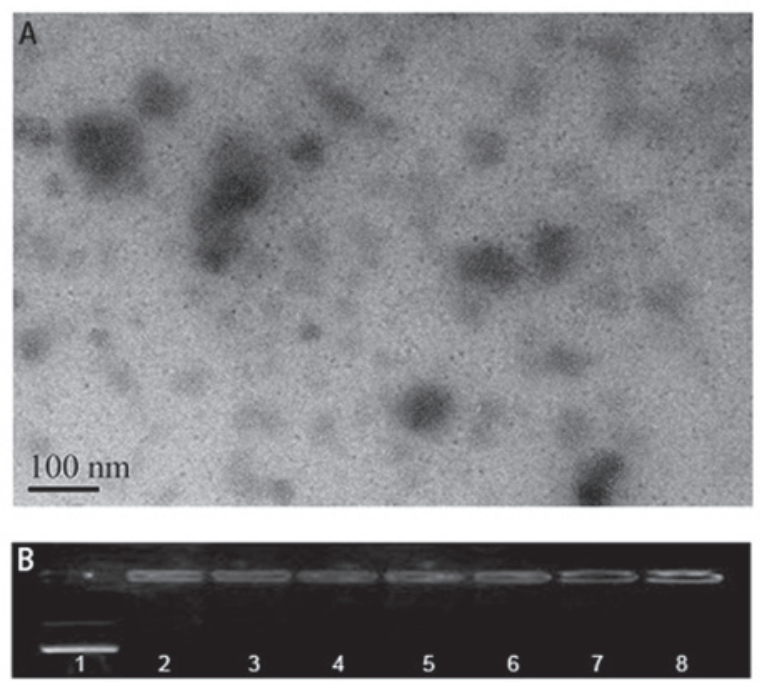

Figure 1. Characterization of L-PEI/pDNA polyplexes. (A) TEM analysis of polyplex morphologies (pDNA/L-PEI, $2 \mu \mathrm{g}: 14 \mu \mathrm{g}$ ). Polyplex particles were formed by electrostatic interactions between L-PEI and pDNA. (B) Agarose gel electrophoresis of $0.5 \mu \mathrm{g}$ enhanced green fluorescent pDNA complexed with various amounts of L-PEI. Lane $1,0 \mu \mathrm{g}$; lane 2, $0.5 \mu \mathrm{g}$; lane 3, $1 \mu \mathrm{g}$; lane 4, $1.5 \mu \mathrm{g}$; lane 5, $2 \mu \mathrm{g}$; lane 6, $2.5 \mu \mathrm{g}$; lane 7, $3 \mu \mathrm{g}$; lane 8, $4 \mu \mathrm{g}$. L-PEI, linear polyethylenimine; pDNA, plasmid DNA.

total volume of $50 \mu 1$. In PBS, retardation of migration was achieved with $0.5 \mu \mathrm{g}$ L-PEI (Fig. 1B).

In vitro transfection studies of neonatal mouse cochlear cultures. The sensory epithelium of four-day-old mouse pups was transfected at various L-PEI to eGFP plasmid weight ratios in order to identify the optimum transfection ratio. A complex comprised of $3 \mu \mathrm{g}$ L-PEI and $1 \mu \mathrm{g}$ pDNA was demonstrated to be able to transfect the outgrowing cells, and it was revealed that the use of $>2 \mu \mathrm{g}$ pDNA with $\geq 5 \mu \mathrm{g}$ L-PEI transfected the fibrocytes in the spiral limbus (data not shown). Of note, when the L-PEI/pDNA ratio was altered to $7: 1 \mu \mathrm{g}$, the cells in the organ of the Corti region were transfected (Fig. 2).

Hair cell damage occurs immediately following transfection. No marked hair cell loss was identified in the control samples. The explants survived well in the nutritional culturing medium, even following $72 \mathrm{~h}$ of culture. As the above level of transfection was only achieved when the L-PEI/pDNA weight ratio was increased to 7:1, the effects of nanoparticles generated at this transfection level on the hair and interdental cells in the spiral limbus was further examined. The otoancorin antibody was applied not only for staining of the interdental cells, but also for better discrimination between the spiral limbus region and the hair cell region under harsh nano-ototoxic conditions. Following addition of the polyplex, oto-nanotoxicity to hair cells immediately commenced (Fig. 3A). Compared with the inner hair cells (IHCs), the outer hair cells (OHCs) were more vulnerable at the acute phase. Following $24 \mathrm{~h}$ of culture with the polyplex, only a sparse population of hair cells remained (Fig. 3B). Following $48 \mathrm{~h}$ of culture, few hair cells survived and the damage had spread to the Hensen and Claudius cells' region (Fig. 3C). Statistically significant differences in the levels of cellular 

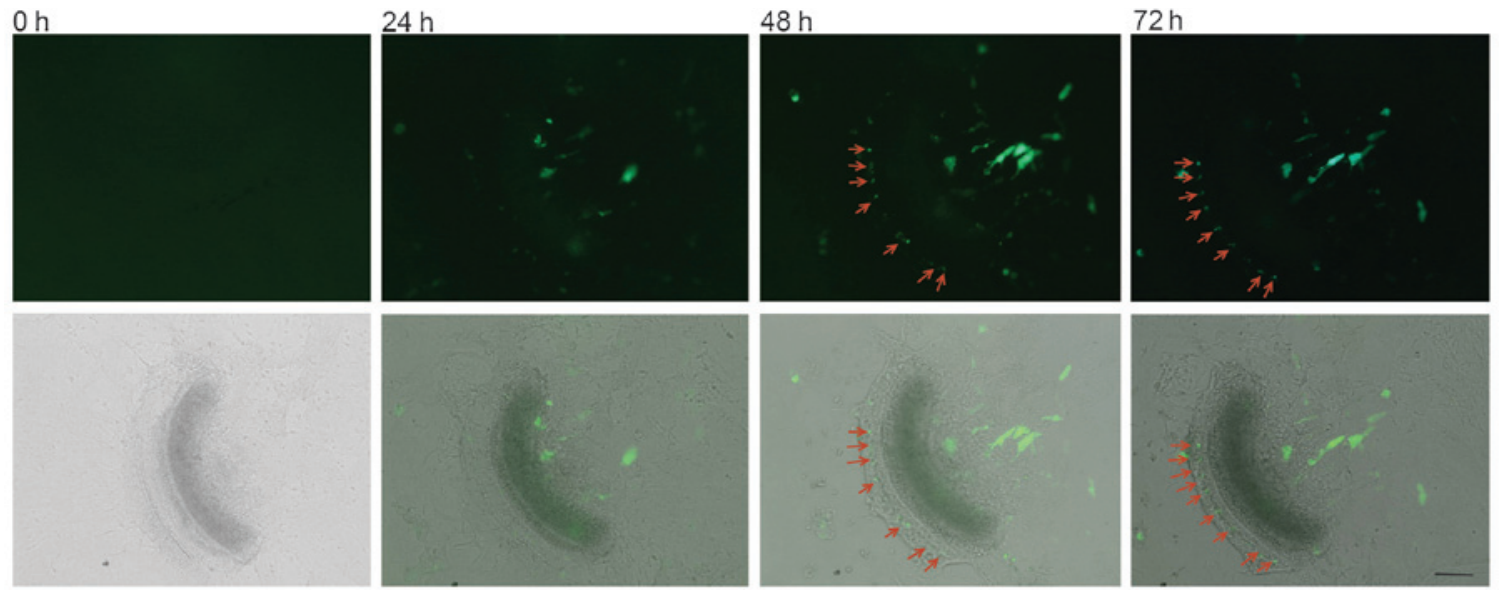

Figure 2. eGFP fluorescence persisted for $\sim 48 \mathrm{~h}$ post-transfection. Transfected cells, which were suggested to be the supporting cells (red arrows) demonstrating highly regular lining of the sensory epithelium region were detected in a middle turn piece, where eGFP expression persisted $>72 \mathrm{~h}$. The lower panel depicts a merged view of immunolabeling of the transfected cells of the upper panel. Scale bar, $200 \mu \mathrm{m}$. eGFP, enhanced green fluorescent protein.
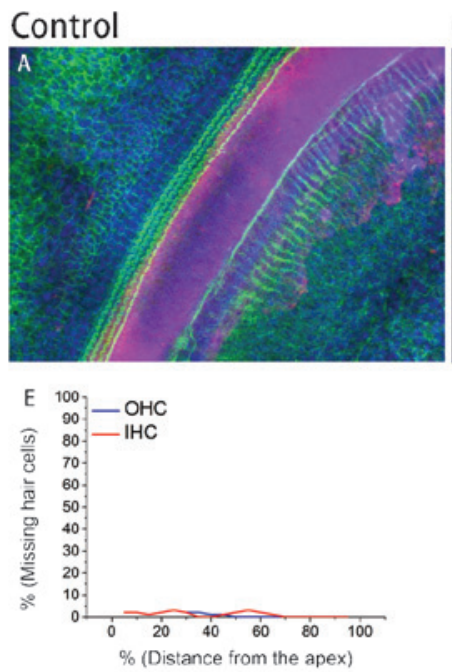

$0 \mathrm{~h}$
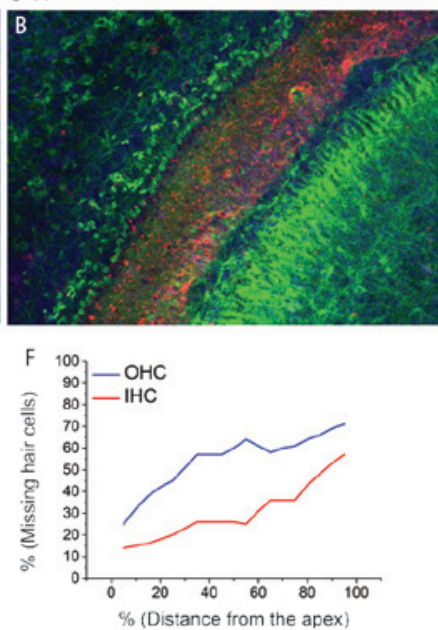

$24 \mathrm{~h}$
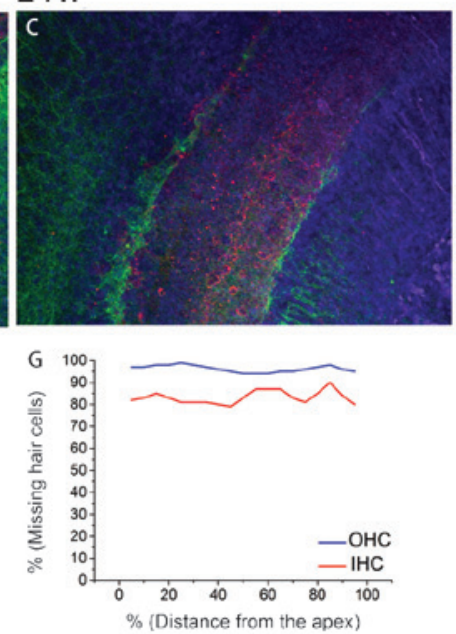
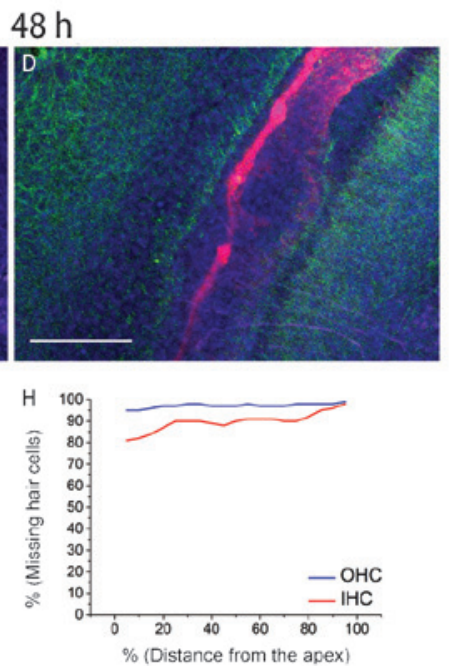

Figure 3. Cell imaging and counting of the cochlear epithelium revealed a dramatic loss of IHCs and OHCs. (A) Orderly alignment of the IHCs and OHCs forms a geometric pattern in the control sample (cultured for $48 \mathrm{~h}$ ). Dynamic damage of hair cells (B) $0 \mathrm{~h}$, (C) $24 \mathrm{~h}$ and (D) $48 \mathrm{~h}$ post-transfection was marked in the sensory epithelium. Scale bar, $100 \mu \mathrm{m}$. (E-H) Hair cell counts. IHC, inner hair cell; OHC, outer hair cell.

loss between each time-group were detected (all $\mathrm{P}<0.05)$ for IHCs and OHCs (Fig. 3E-H). Counting random regions of interdental cells revealed that statistical divergence also existed (all $\mathrm{P}<0.05)$.

Cellular toxicity occurs immediately following transfection. The toxic effects of the L-PEI-pDNA polyplexes were further evaluated by TEM. The hair cells and supporting cells were functioning effectively, even on the fourth day of explantation. The cell membranes were intact, stereocillia were orderly arranged and the organelles appeared normal (Fig. 4A). However, following incubation with the polyplex, it was demonstrated that the nanoparticles were able to penetrate into the cell bodies of the hair cells and their supporting cells (Fig. 4B-D) (21-23). Immediately following transfection, large quantities of bubbles were detected within the sensory epithelial cells, stereocilla were partially damaged and mitochondrial numbers were significantly reduced. Approximately $24 \mathrm{~h}$ later, the sensory epithelium detached from the basilar membrane, the cell membrane was ruptured and large quantities of cytoplasm were lost from the cell bodies. Within certain sections, condensed chromatin in the nucleus and apoptotic bodies were identified. Following a further $24 \mathrm{~h}$ of incubation, the cells died. This phenomenon was in accordance with the results of the immunofluorescent staining analysis.

\section{Discussion}

Non-viral gene delivery has emerged as a potential alternative to conventional viral transfection systems. The structure and physical properties of synthetic gene carriers, including their size, shape, side groups and charge, influence their association with nucleic acids, intracellular pathways and overall delivery efficiency $(24,25)$. Since the first published examination of PEI as a gene delivery vehicle (26), numerous studies aimed at elucidating its (or modified PEI's) potential role as a nanocarrier for DNA, RNA and oligonucleotides (19). The development 

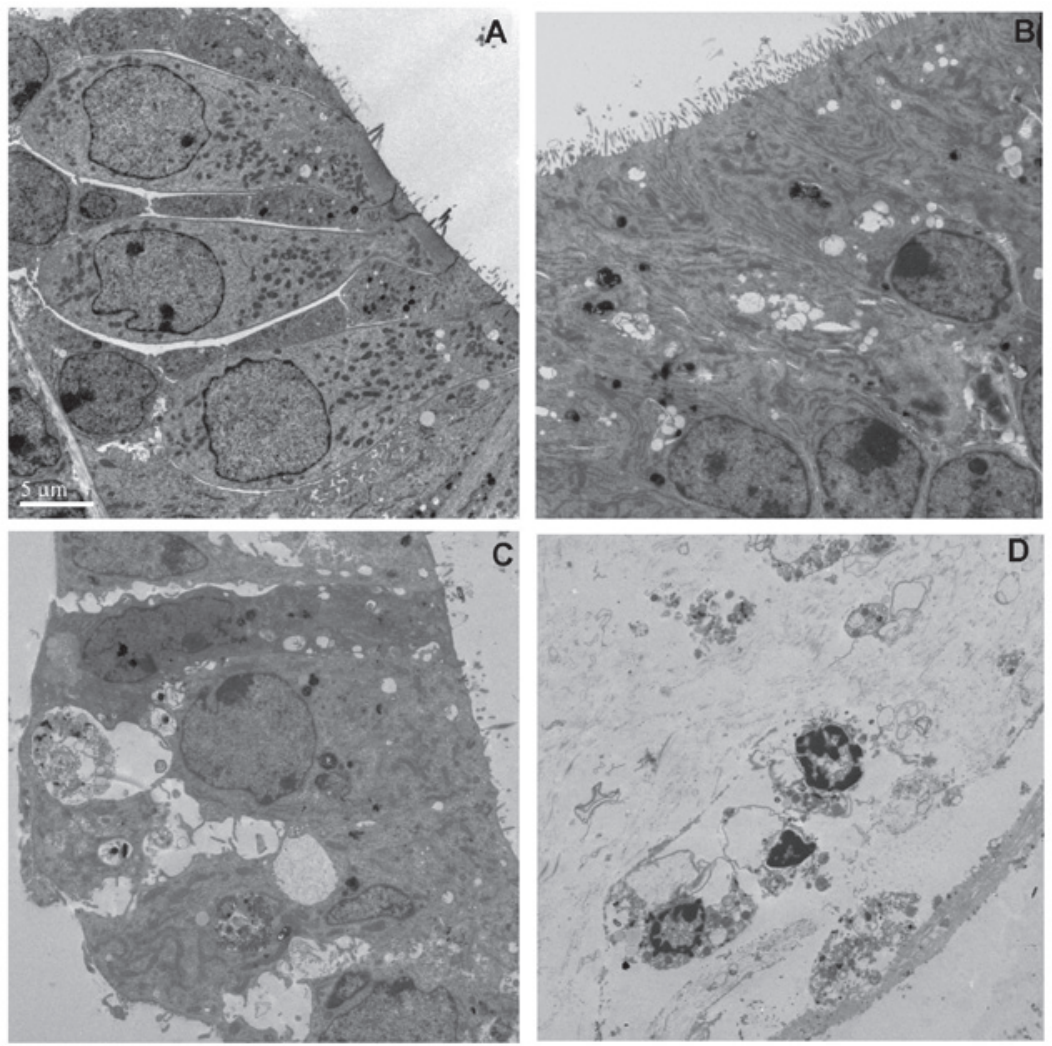

Figure 4. Analysis of ultrathin TEM sections within the organ of Corti indicated toxic effects under identical concentrations of L-PEI and plasmid. (A) Sensory epithelium revealed dense cell packing and limited extracellular fluid spaces in a non-transfected control sample. (B-D) TEM images taken $0,24,48 \mathrm{~h}$ post-transfection indicated apoptosis-/necrosis-like changes, induced by L-PEI/plasmid DNA nanoparticle transfection. TEM, transmission electron microscope; L-PEI, linear polyethylenimine. Scale bar, $5 \mu \mathrm{m}$.

of PEI represented significant progress in the field of non-viral gene transfer (27), and to date, PEI remains one of the most effective and frequently utilized non-viral vectors (28).

PEI is a highly positively charged, synthetic polymer, which is comprised of primary, secondary and tertiary amino groups at a 1:2:1 ratio (20). Every third atom of PEI is a nitrogen that is able to be protonated, and $20 \%$ of these nitrogens are protonated under normal physiological conditions (29). PEI is therefore able to alter its ionization state over a broad $\mathrm{pH}$ range, conferring significant buffering capacity (20). Via electrostatic interaction with negatively charged DNA, these agents typically form toroidal or spherical particles. Fourier transform infrared analysis revealed that DNA is maintained in B form following complexation with various amounts, molecular weights or forms of PEI (30).

The positively charged PEI polyplexes are able to interact with highly anionic polysaccharides, for example glycosaminoglycans, including hyaluronic acid, chondroitin sulfate and heparan sulfate, that are located in the extracellular space and on the surface of the majority of cells (31-33). Subsequently, the polyplexes are internalized via endocytosis or pinocytosis (34-35). PEI therefore efficiently mediates gene delivery without the requirement for exogenous endosomolytic agents. According to the proton sponge hypothesis, during the transition from the plasma membrane $(\mathrm{pH} 7)$ to the early endosome ( $\mathrm{pH}$ 6.5), late endosome ( $\mathrm{pH}$ 5.5) and finally to the lysosome (pH 5), ionizable PEI exhibits broad pKa values and functions as a buffer by pumping additional protons along with the concur- rent influx of chloride ions, which increases the ionic strength inside the endolysosome $(29,36)$. This results in an influx of water, osmotic swelling and endolysosomal bursting, resulting in the escape of the polyplex in order to protect the DNA in the cell $(29,36)$. However, Godbey et al (27) demonstrated that the transfection efficiency of PEI is not a result of its lysosomal buffering; instead, PEI moves towards the nucleus while keeping the complexed plasmids tightly condensed and protected.

Protein, microtubules and other organelles are all able to perturb polyplex movement. Naked DNA moves slowly through the cytoplasm (5). It has been suggested that positively charged polyplexes are actively transported by microtubules and microfilaments (37-40). Polyplexes may move along microtubules via non-specific interactions with anionic microtubules or motor proteins, or they may rely upon the natural transport of endolysosomes along the microtubules. Polyplexes may be delivered to the perinuclear region via the microtuble and actin networks (41-43). Nuclear entry is used to transport objects $<40 \mathrm{~nm}$ in diameter (44), and certain polyplexes or free plasmids may enter the nucleus via this mechanism, while numerous polyplexes or plasmids are localized to the perinuclear region where they await rupture of the nuclear membrane envelope during cell division (45). PEI also possesses an additional mechanism for mediating the nuclear entry of pDNA which does not require cell division, as post-mitotic cells, including neurons, are able to be transfected in vitro and in vivo. However, the intracellular barriers to plasmid trafficking vary quantitatively with cell type $(41,46,47)$. 
Originally, $0.5 \%$ low-molecular weight PEI (molecular weight, 1,800) in cacodylate buffer was used as a cationic tracer for the identification of anionic sites created by chondroitin- and heparin-rich glycosaminoglycan on the capillary and subepithlial basement membrane of the stria vascularis, spiral ligament, spiral limbus, Reissner's membrane and the vestibular sensory epithlium (ampulla and macula) $(48,49)$. These anionic sites were considered to be associated with a negative charge blood-labyrinth/perilymphatic-endolymphatic barrier for electrically charged macromolecules and ions, and with the maintenance of steep chemical gradients (50). This barrier already exists in four-day-old rats and remains immature in the early postnatal period. Once damaged, the biological membrane barrier becomes more permeable, resulting in hearing impairment (51). Though low-molecular weight PEIs are less toxic (52), they lack effective transfection properties as, due to their low positive charge, they are incapable of effectively condensing DNA (53). Additionally, their low associated surface charge does not induce effective cellular uptake via charge-mediated interactions (53).

The forms of PEI most widely used for cellular transfection are $25 \mathrm{kDa}$ L-PEI, branched PEI (B-PEI) and $22 \mathrm{kDa}$ L-PEI; however, their transfection abilities differ. The greater transfection efficiency of L-PEI may be a result of its inherent kinetic instability under salt conditions (54). The $22-\mathrm{kDa}$ L-PEI has been demonstrated to have higher transfection activity in vivo when complexed with plasmids in salt-free buffer and administered intravenously (55-57). Under equivalent salt conditions, the transfection efficiency of $22-\mathrm{kDa}$ L-PEI is higher than that of 25-kDa B-PEI. Tan et al (14) used 22-kDa L-PEI (ExGen500) diluted in 5\% (w/v) glucose solution for the transfection of cochlear cells in vitro and in vivo. Using the relatively low nitrogen:phosphorus ratios (26) (the ratio of moles in the amine group of cationic polymers to those of the phosphate groups), neither syringe transfection nor weeks of infusion via the osmotic pump yielded satisfactory levels of transfection in vivo (14). In the present study, PBS was selected as the dilution medium as the number of PEI-based nanoparticles generated in salt-free conditions were reported to inefficiently transfect the cultured cell lines. Furthermore, PBS more closely mimicked the high ionic strength of the cochlear lymphatic system. In accordance with the results of previous experiments, which demonstrated that supporting cells were able to be transfected by L-PEI-pDNA nanoparticles, the results of the present study also indicated that the cells of the sensory epithelium may be transfected. Furthermore, as the hair cells barely survived following transfection, eGFP protein was likely expressed by the supporting cells.

Certain concerns have emerged regarding the toxicity of nanoparticle delivery systems (58). In vitro studies have demonstrated that the cytotoxicity of PEI may potentially be a result of the presence of excess free polymer following complexation with DNA, and its limited biodegradability (59-61). This lack of biodegradability may be attributed to the highly branched non-degradable methylene backbone, and the high cationic charge density of PEI, which is inherently toxic to normal tissues if the carrier is not degraded following internalization $(62,63)$. The branched form of PEI exhibits a higher condensation ability and transfection efficiency, but is associated with higher toxicity (54). Furthermore, the endocytosed nanoparticles may induce oxidative stress by stimulating the production of intracellular reactive oxygen species, a process which represents the first event in a cellular toxicity cascade, where multiple gene expression alterations are elicited in cells in vitro and in vivo (64). Moghimi et al (65) revealed that $25 \mathrm{kDa}$ B-PEI induced membrane damage and initiated apoptosis in three clinically relevant human cell lines. As early as $30 \mathrm{~min}$ following transfection, compromised membrane integrity resulted in necrotic-like changes. Significant lactate dehydrogenase was released and phosphatidylserine was translocated from the inner plasma membrane to the cell surface. At $24 \mathrm{~h}$ post-transfection, PEI-induced channel formation in the outer mitochondrial membrane triggers a 'mitochondrially mediated apoptotic program', pro-apoptotic cytochrome $c$ is released and the apopotic pathway is activated (65-67). Lin et al (68) additionally demonstrated the involvement of autophagy. The results of the present study supported this hypothesis, and further indicated that the nanoparticles based on $25 \mathrm{kDa}$ L-PEI resulted in similar oto-nanotoxicity effects in the cultured cochlear epithelium. The auditory sensory epithelial cells (in particular, the outer and inner hair cells) were degenerated in all experimental groups, more markedly so in the $48 \mathrm{~h}$ group, in addition to other cell types, for example interdental cells in the spiral limbus. However, the hair cells appeared to be more sensitive to oto-nanotoxicity than interdental cells. These differences in the extent of oto-nanotoxicity were suggested to be associated with the inherent variations in the uptake and removal ability of various cell types, which facilitate their ability to deal with nanomaterials, including antioxidant levels or repair mechanisms (69). Using zebrafish as a model animal for nanocytotoxic research (70), Rizzo et al (71) verified that the 25-kDa L-PEI prevented proper embryo development at concentrations as low as $0.01 \mu \mathrm{g} / \mu \mathrm{l}$. Such potentially hazardous effects, which are intrinsic to multiple synthetic polymer vector carriers, including PEI and its derivatives, represent a significant limitation to their use. The present study demonstrated that the use of PEI-derived gene delivery vehicles in the inner ear remains limited, due to their relatively high cytotoxicity.

Recent developments in nanomedicine have revealed novel insights into inner ear gene therapy (72). However, current knowledge regarding nanotoxicity is dwarfed by what remains to be elucidated (69). Fears over the potential dangers of nanomedicine may be exaggerated, but are not necessarily unfounded. The results of the present study revealed that the cultured hearing sensory epithelium was able to be transfected by the classical non-viral cationic polymer PEI-based nanoparticles. However, the excess polyplexes and cationic applications of PEI hampered its effectiveness by inducing nano-ototoxicity to the delicate cochlear structures. The molecular mechanisms underlying the interactions between nanoparticles and cells, and a more detailed nanotoxicty profile require further elucidation. For these reasons, significant obstacles remain regarding the use of nanoparticle therapeutics, prior to their evaluation in clinical trials and subsequent use for the delivery of therapeutics in humans. Novel high-throughput approaches to design and screening may aid in the assessment of chemically and physically diverse nanomaterials, enabling the identification of a successful, highly efficient, biocompatible, biodegradable, 
non-toxic next-generation polymer vectors for use in inner ear gene therapy $(28,73)$.

\section{Acknowledgements}

This study was supported by the Jiangsu Provincial Natural Science Foundation of China (no. BK2010104).

\section{References}

1. Lustig LR and Akil O: Cochlear gene therapy. Curr Opin Neurol 25: 57-60, 2012.

2. Ryan AF, Mullen LM and Doherty JK: Cellular targeting for cochlear gene therapy. Adv Otorhinolaryngol 66: 99-115, 2009.

3. Marshall E: Gene therapy what to do when clear success comes with an unclear risk? Science 298: 510-511, 2002.

4. Sadelain M: Insertional oncogenesis in gene therapy: how much of a risk? Gene Ther 11: 569-573, 2004.

5. Pack DW, Hoffman AS, Pun S and Stayton PS: Design and development of polymers for gene delivery. Nat Rev Drug Discov 4: 581-593, 2005.

6. Wang W, Li W, Ma N and Steinhoff G: Non-viral gene delivery methods. Curr Pharm Biotechnol 14: 46-60, 2013.

7. Zhou T, Llizo A, Wang C, Xu G and Yang Y: Nanostructureinduced DNA condensation. Nanoscale 5: 8288-8306, 2013.

8. Godbey WT, Wu KK and Mikos AG: Poly(ethylenimine) and its role in gene delivery. J Control Release 60: 149-160, 1999.

9. Wanga P, Zhang P, Huang J, Li M and Chen X: Trichostatin a protects against cisplatin-induced ototoxicity by regulating expression of genes related to apoptosis and synaptic function. Neurotoxicology 37: 51-62, 2013.

10. Bergen JM, Park IK, Horner PJ and Pun SH: Nonviral approaches for neuronal delivery of nucleic acids. Pharm Res 25: 983-998, 2008

11. Pérez-Martínez FC, Carrión B and Ceña V: The use of nanoparticles for gene therapy in the nervous system. J Alzheimers Dis 31: 697-710, 2012.

12. Kim DK, Park SN, Park KH, et al: Development of a drug delivery system for the inner ear using poly(amino acid)-based nanoparticles. Drug Deliv: Jan 22, 2014 (Epub ahead of print).

13. Pritz CO, Dudás J, Rask-Andersen H, Schrott-Fischer A and Glueckert R: Nanomedicine strategies for drug delivery to the ear. Nanomedicine (Lond) 8: 1155-1172, 2013.

14. Tan BT, Foong KH, Lee MM and Ruan R: Polyethylenimine-mediated cochlear gene transfer in guinea pigs. Arch Otolaryngol Head Neck Surg 134: 884-891, 2008.

15. Nel A, Xia T, Mädler L and Li N: Toxic potential of materials at the nano level. Science 311: 622-627, 2006.

16. Calarco A, Bosetti M, Margarucci S, et al: The genotoxicity of PEI-based nanoparticles is reduced by acetylation of polyethylenimine amines in human primary cells. Toxicol Lett 218: 10-17, 2013.

17. El-Ansary A and Al-Daihan S: On the toxicity of therapeutically used nanoparticles: an overview. J Toxicol 2009: 754810, 2009.

18. Sobkowicz HM, Loftus JM and Slapnick SM: Tissue culture of the organ of Corti. Acta Otolaryngol Suppl 502: 3-36, 1993.

19. Kichler A: Gene transfer with modified polyethylenimines. J Gene Med 1: S3-S10, 2004.

20. Akinc A, Thomas M, Klibanov AM and Langer R: Exploring polyethylenimine-mediated DNA transfection and the proton sponge hypothesis. J Gene Med 7: 657-663, 2005.

21. Zhang W, Zhang Y,Löbler M, et al: Nuclear entry of hyperbranched polylysine nanoparticles into cochlear cells. Int J Nanomedicine 6: 535-546, 2011.

22. Zou J, Saulnier P, Perrier T, et al: Distribution of lipid nanocapsules in different cochlear cell populations after round window membrane permeation. J Biomed Mater Res B Appl Biomater 87: 10-18, 2008.

23. Roy S, Johnston AH, Newman TA, et al: Cell-specific targeting in the mouse inner ear using nanoparticles conjugated with a neurotrophin-derived peptide ligand: potential tool for drug delivery. Int J Pharm 390: 214-224, 2010.

24. Tang MX and Szoka FC: The influence of polymer structure on the interactions of cationic polymers with DNA and morphology of the resulting complexes. Gene Ther 4: 823-832, 1997.

25. Shim MS and Kwon YJ: Controlled cytoplasmic and nuclear localization of plasmid DNA and siRNA by differentially tailored polyethylenimine. J Control Release 133: 206-213, 2009.
26. Boussif O, Lezoualch F, Zanta MA, et al: A versatile vector for gene and oligonucleotide transfer into cells in culture and-in vivo polyethylenimine. Proc Natl Acad Sci USA 92: 7297-7301, 1995.

27. Godbey WT, Barry MA, Saggau P, Wu KK and Mikos AG: Poly(ethylenimine)-mediated transfection: a new paradigm for gene delivery. J Biomed Mater Res 51: 321-328, 2000.

28. Patnaik S and Gupta KC: Novel polyethylenimine-derived nanoparticles for in vivo gene delivery. Expert Opin Drug Deliv 10: 215-228, 2013

29. Behr JP: The proton sponge: a trick to enter cells the viruses did not exploit. Chimia International Journal for Chemistry 51: 34-36, 1997.

30. Choosakoonkriang S, Lobo BA, Koe GS, Koe JG and Middaugh CR: Biophysical characterization of PEI/DNA complexes. J Pharm Sci 92: 1710-1722, 2003.

31. Ruponen M, Honkakoski P, Rönkkö S, Pelkonen J, Tammi M and Urtti A: Extracellular and intracellular barriers in non-viral gene delivery. J Control Release 93: 213-217, 2003.

32. Wiethoff CM, Smith JG, Koe GS and Middaugh CR: The potential role of proteoglycans in cationic lipid-mediated gene delivery. Studies of the interaction of cationic lipid-DNA complexes with model glycosaminoglycans. J Biol Chem 276: 32806-32813, 2001.

33. Artzner F, Zantl R and Rädler JO: Lipid-DNA and lipid-polyelectrolyte mesophases: structure and exchange kinetics. Cell Mol Biol (Noisy-le-grand) 46: 967-978, 2000.

34. Mislick KA and Baldeschwieler JD: Evidence for the role of proteoglycans in cation-mediated gene transfer. Proc Natl Acad Sci USA 93: 12349-12354, 1996.

35. Wiethoff CM and Middaugh CR: Barriers to nonviral gene delivery. J Pharm Sci 92: 203-217, 2003.

36. Payne CK: Imaging gene delivery with fluorescence microscopy. Nanomedicine (Lond) 2: 847-860, 2007.

37. De Smedt SC, Demeester J and Hennink WE: Cationic polymer based gene delivery systems. Pharm Res 17: 113-126, 2000.

38. Pollard H, Remy JS, Loussouarn G, Demolombe S, Behr JP and Escande D: Polyethylenimine but not cationic lipids promotes transgene delivery to the nucleus in mammalian cells. J Biol Chem 273: 7507-7511, 1998.

39. Wang T, Upponi JR and Torchilin VP: Design of multifunctional non-viral gene vectors to overcome physiological barriers: dilemmas and strategies. Int J Pharm 427: 3-20, 2012.

40. Grosse S, Aron Y, Thévenot G, Monsigny M and Fajac I: Cytoskeletal involvement in the cellular trafficking of plasmid/PEI derivative complexes. J Control Release 122: 111-117, 2007.

41. Suh J, Wirtz D and Hanes J: Efficient active transport of gene nanocarriers to the cell nucleus. Proc Natl Acad Sci USA 100: 3878-3882, 2003.

42. Bausinger R, von Gersdorff $\mathrm{K}$, Braeckmans $\mathrm{K}$, et al: The transport of nanosized gene carriers unraveled by live-cell imaging. Angew Chem Int Ed Engl 45: 1568-1572, 2006.

43. Kulkarni RP, Wu DD, Davis ME and Fraser SE: Quantitating intracellular transport of polyplexes by spatio-temporal image correlation spectroscopy. Proc Natl Acad Sci USA 102: 7523-7528, 2005.

44. Pante $\mathrm{N}$ and Kann M: Nuclear pore complex is able to transport macromolecules with diameters of about $39 \mathrm{~nm}$. Mol Biol Cell 13: 425-434, 2002.

45. Grosse S, Aron Y, Thévenot G, François D, Monsigny M and Fajac I: Potocytosis and cellular exit of complexes as cellular pathways for gene delivery by polycations. J Gene Med 7: 1275-1286, 2005.

46. Godbey WT, Wu KK and Mikos AG: Tracking the intracellular path of poly(ethylenimine)/DNA complexes for gene delivery. Proc Natl Acad Sci USA 96: 5177-5181, 1999.

47. Abdallah B, Hassan A, Benoist C, Goula D, Behr JP and Demeneix BA: A powerful nonviral vector for in vivo gene transfer into the adult mammalian brain: polyethylenimine. Hum Gene Ther 7: 1947-1954, 1996.

48. Suzuki M, Kitamura K and Nomura Y: Anionic sites of the basement membrane of the labyrinth. Acta Otolaryngol Suppl 481: 112-115, 1991.

49. Suzuki M and Kaga K: Effect of cisplatin on the negative charge barrier in strial vessels of the guinea pigs. A transmission electron microscopic study using polyethyleneimine molecules. Eur Arch Otorhinolaryngol 253: 351-355, 1996.

50. Yamasoba T, Suzuki M and Kaga K: Influence of chronic kanamycin administration on basement membrane anionic sites in the labyrinth. Hear Res 102: 116-124, 1996. 
51. Suzuki M, Yamasoba T and Kaga K: Development of the blood-labyrinth barrier in the rat. Hear Res 116: 107-112, 1998.

52. Breunig M, Lungwitz U, Liebl R, et al: Gene delivery with low molecular weight linear polyethylenimines. J Gene Med 7: $1287-1298,2005$.

53. Godbey WT, Wu KK and Mikos AG: Size matters: molecular weight affects the efficiency of poly(ethylenimine) as a gene delivery vehicle. J Biomed Mater Res 45: 268-275, 1999.

54. Wightman L, Kircheis R, Rössler V, et al: Different behavior of branched and linear polyethylenimine for gene delivery in vitro and in vivo. J Gene Med 3: 362-372, 2001.

55. Goula D, Remy JS, Erbacher P, et al: Size, diffusibility and transfection performance of linear PEI/DNA complexes in the mouse central nervous system. Gene Ther 5: 712-717, 1998.

56. Goula D, Benoist C, Mantero S, Merlo G, Levi G and Demeneix BA: Polyethylenimine-based intravenous delivery of transgenes to mouse lung. Gene Ther 5: 1291-1295, 1998.

57. Bragonzi A, Dina G, Villa A, et al: Biodistribution and transgene expression with nonviral cationic vector/DNA complexes in the lungs. Gene Ther 7: 1753-1760, 2000.

58. Maynard AD, Aitken RJ, Butz T, et al: Safe handling of nanotechnology. Nature 444: 267-269, 2006.

59. Boeckle S, von Gersdorff K, van der Piepen S, Culmsee C, Wagner E and Ogris M: Purification of polyethylenimine polyplexes highlights the role of free polycations in gene transfer. J Gene Med 6: 1102-1111, 2004.

60. Thomas M, Ge Q, Lu JJ, Chen J and Klibanov AM: Cross-linked small polyethylenimines: while still nontoxic, deliver DNA efficiently to mammalian cells in vitro and in vivo. Pharm Res 22 373-380, 2005.

61. Forrest ML, Koerber JT and Pack DW: A degradable polyethylenimine derivative with low toxicity for highly efficient gene delivery. Bioconjug Chem 14: 934-940, 2003.

62. Xiong MP, Forrest ML, Ton G, Zhao A, Davies NM and Kwon GS: Poly(aspartate-g-PEI800), a polyethylenimine analogue of low toxicity and high transfection efficiency for gene delivery. Biomaterials 28: 4889-4900, 2007.
63. Fischer D, Li Y, Ahlemeyer B, Krieglstein J and Kissel T: In vitro cytotoxicity testing of polycations: influence of polymer structure on cell viability and hemolysis. Biomaterials 24: 1121-1131, 2003.

64. Kabanov AV: Polymer genomics: an insight into pharmacology and toxicology of nanomedicines. Adv Drug Deliv Rev 58: 1597-1621, 2006.

65. Moghimi SM, Symonds P, Murray JC, Hunter AC, Debska g and Szewczyk A: A two-stage poly(ethylenimine)-mediated cytotoxicity: implications for gene transfer/therapy. Mol Ther 11: 990-995, 2005.

66. Florea BI, Meaney C, Junginger HE and Borchard G: Transfection efficiency and toxicity of polyethylenimine in differentiated Calu-3 and nondifferentiated COS-1 cell cultures. AAPS PharmSci 4: E12, 2002.

67. Klemm AR, Young D and Lloyd JB: Effects of polyethyleneimine on endocytosis and lysosome stability. Biochem Pharmacol 56: 41-46, 1998.

68. Lin CW, Jan MS, Kuo JH, Hsu LJ and Lin YS: Protective role of autophagy in branched polyethylenimine $(25 \mathrm{~K})$ - and poly(L-lysine) (30-70K)-induced cell death. Eur J Pharm Sci 47: 865-874, 2012

69. Park MV, Lankveld DP, van Loveren H and de Jong WH: The status of in vitro toxicity studies in the risk assessment of nanomaterials. Nanomedicine (Lond) 4: 669-685, 2009.

70. Fako VE and Furgeson DY: Zebrafish as a correlative and predictive model for assessing biomaterial nanotoxicity. Adv Drug Deliv Rev 61: 478-486, 2009.

71. Rizzo LY, Golombek SK, Mertens ME, et al: In vivo nanotoxicity testing using the zebrafish embryo assay. J Mater Chem B Mater Biol Med 1: 3918-3925, 2013.

72. Caruthers SD, Wickline SA and Lanza GM: Nanotechnological applications in medicine. Curr Opin Biotechnol 18: 26-30, 2007.

73. Lai DY: Toward toxicity testing of nanomaterials in the $21 \mathrm{st}$ century: a paradigm for moving forward. Wiley Interdiscip Rev Nanomed Nanobiotechnol 4: 1-15, 2012. 